\title{
Correction to: Mechanical and thermal properties of hyperbranched poly( $\varepsilon$-caprolactone) modified graphene/epoxy composites
}

\author{
Lingran Hou ${ }^{1} \cdot$ Jian Gao ${ }^{1} \cdot$ Hong Ruan ${ }^{1} \cdot \mathrm{Xu} \mathrm{Xu}^{1} \cdot$ Shaorong Lu ${ }^{1}$
}

Published online: 10 May 2020

(C) The Polymer Society, Taipei 2020

Correction to: Journal of Polymer Research https://doi.org/10.1007/s10965-020-2008-x

The original version of this article unfortunately contained a mistake. Fig. 2 was processed incorrectly. The correct Fig. 2 is The original article has been corrected. now shown here.

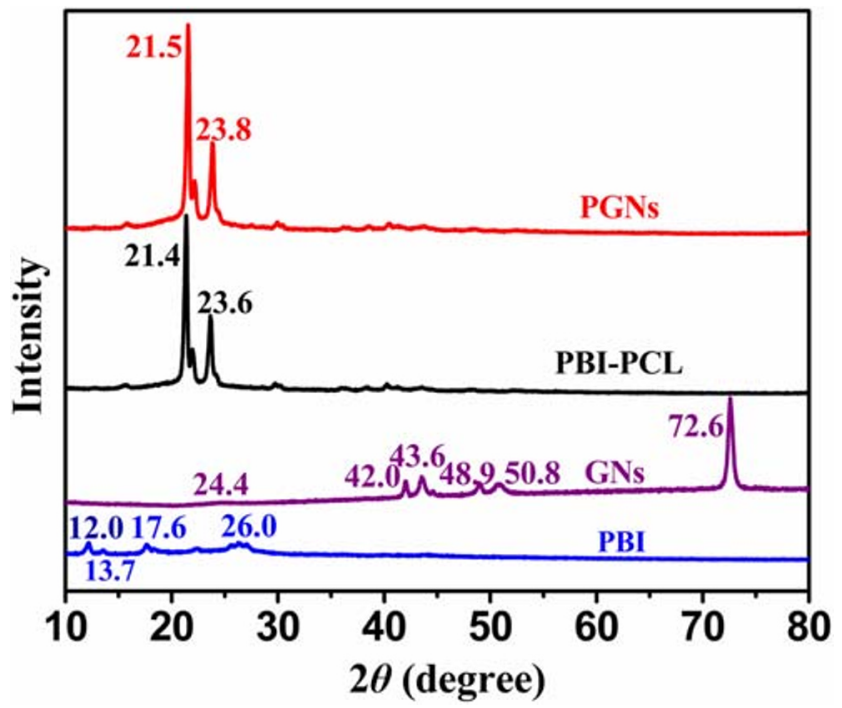

Fig. 2 WAXD curves of GNs, PBI, PBI-PCL and PGNs

The online version of the original article can be found at https://doi.org/ 10.1007/s10965-020-2008-x

$\triangle$ Hong Ruan

ruanhong6891@126.com

$\triangle \mathrm{Xu} \mathrm{Xu}$

xuxu8485@163.com

$\triangle$ Shaorong $\mathrm{Lu}$

lushaor@163.com

Key Laboratory of New Processing Technology for Nonferrous Metals and Materials, Ministry of Education, College of Materials Science and Engineering, Guilin University of Technology,

Guilin 541004, China 